\title{
A Task-Dependent Causal Role for Low-Level Visual Processes in Spoken Word Comprehension
}

\author{
Markus Ostarek \\ Max Planck Institute for Psycholinguistics, Nijmegen, the \\ Netherlands, and International Max Planck Research School for \\ Language Sciences, Nijmegen, the Netherlands
}

\author{
Falk Huettig \\ Max Planck Institute for Psycholinguistics, Nijmegen, the \\ Netherlands, and Donders Institute for Brain, Cognition, \& \\ Behavior, Nijmegen, the Netherlands
}

\begin{abstract}
It is well established that the comprehension of spoken words referring to object concepts relies on high-level visual areas in the ventral stream that build increasingly abstract representations. It is much less clear whether basic low-level visual representations are also involved. Here we asked in what task situations low-level visual representations contribute functionally to concrete word comprehension using an interference paradigm. We interfered with basic visual processing while participants performed a concreteness task (Experiment 1), a lexical-decision task (Experiment 2), and a word class judgment task (Experiment 3). We found that visual noise interfered more with concrete versus abstract word processing, but only when the task required visual information to be accessed. This suggests that basic visual processes can be causally involved in language comprehension, but that their recruitment is not automatic and rather depends on the type of information that is required in a given task situation.
\end{abstract}

Keywords: language comprehension, semantic processing, visual processing

Supplemental materials: http://dx.doi.org/10.1037/xlm0000375.supp

In recent decades, the view that the conceptual system underlying language comprehension is to a non-negligible extent based on sensory-motor (and potentially other kinds of) experience has been very dominant. In recognition of the symbol grounding problem (Harnad, 1990), most contemporary theories of conceptual processing assume that it relies at least partly on modalityspecific systems (e.g., Barsalou, 1999, 2008, 2016; Binder \& Desai, 2011; Meteyard, Cuadrado, Bahrami, \& Vigliocco, 2012). Binder and colleagues (2016), for instance, have proposed a framework of conceptual processing based on a set of primitive experiential features that capture the various kinds of experience associated with a given concept (sensory, motor, affective, social, etc.). Their approach focuses on the kinds of cognitive/neural experience related to a concept meaning that, for instance, all neural states triggered by encounters with dogs are part of the experience

This article was published Online First January 23, 2017.

Markus Ostarek, Max Planck Institute for Psycholinguistics, Nijmegen, the Netherlands, and International Max Planck Research School for Language Sciences, Nijmegen, the Netherlands; Falk Huettig, Max Planck Institute for Psycholinguistics, and Donders Institute for Brain, Cognition, \& Behavior, Nijmegen, the Netherlands.

Markus Ostarek developed the study concept. Both authors contributed to the study design. Testing and data collection were performed by Markus Ostarek. Markus Ostarek performed the data analysis and interpretation under the supervision of Falk Huettig. Markus Ostarek drafted the manuscript, and Falk Huettig provided critical revisions. Both authors approved the final version of the manuscript for submission.

Correspondence concerning this article should be addressed to Markus Ostarek, Max Planck Institute for Psycholinguistics, PO Box 310, 6500 AH Nijmegen, the Netherlands. E-mail: markus.ostarek@mpi.nl related to the concept $d o g$. A model based on such experiential attributes was recently used to predict brain activation patterns in response to sentences (Anderson et al., 2016). Relevant for the present study, their model predicts that object concepts tend to rely on visual processes. An important question is what types of visual processes are involved during (e.g., spoken) word processing. Here, we investigated the recruitment of low-level visual processes during object word processing and their dependence on task demands.

The visual system has been implicated in the processing of object concepts in the past decades based on neuroimaging studies that localized their neural correlates to high-level visual cortex that is generally assumed to build increasingly holistic object representations along the posterior-to-anterior axis during perception (Bracci \& Op de Beeck, 2016; DiCarlo \& Cox, 2007). Initial univariate fMRI studies on object recognition localized selective activation in response to pictures of animate versus inanimate items to distinct portions of fusiform gyrus and lateral occipital cortex (Chao, Haxby, \& Martin, 1999; Chao, Weisberg, \& Martin, 2002; for review see Martin, 2007). More recently, several fMRI studies using multivariate pattern analysis (MVPA) reported successful decoding of conceptual categories based on picture stimuli from ventral temporal areas (Haxby et al., 2001; Shinkareva et al., 2008). Similar results have been obtained using written words (Devlin, Rushworth, \& Matthews, 2005) as well as spoken words (Noppeney, Price, Penny, \& Friston, 2006), and recent MVPA studies managed to decode the conceptual category across different input modalities from activity patterns in ventral occipitotemporal cortex (Shinkareva et al., 2011; Simanova et al., 2014). Finally, several studies suggest that lesions in visual association cortex lead to specific impairments for concepts that depend on 
visual knowledge (Capitani et al., 2009; Damasio, Tranel, Grabowski, Adolphs, \& Damasio, 2004; Tranel, Damasio, \& Damasio, 1997). Overall, there seems to be a fair amount of consensus that high-level visual representations are consistently used for conceptual processing of concrete objects because they provide representations that are both abstract and grounded (Barsalou, 2016; Binder \& Desai, 2011; Binder, Desai, Graves, \& Conant, 2009; Fernandino, Binder, et al., 2015; Martin, 2007), although it is certainly still debated to what extent sensory systems and conceptual systems overlap and to what extent they are separate (Binder, 2016; Goldinger et al., 2016; Mahon, 2015).

For the question of what types of visual processes are involved it is important to note that the relative consistency of the neural systems recruited by certain types of concepts does not imply conceptual stability. For one thing, even the typical category effects (such as inanimate vs. animate) are localized to varying cortical areas across studies (Devlin et al., 2002; Thompson-Schill, 2003; Martin \& Chao, 2001; for a review see Gerlach, 2007). Moreover, context effects in language processing are ubiquitous (Hoenig, Sim, Bochev, Herrnberger, \& Kiefer, 2008; Kiefer \& Martens, 2010; Lebois, Wilson-Mendenhall, \& Barsalou, 2015; Nieuwland \& van Berkum, 2006; Solomon \& Barsalou, 2004; Tanenhaus, Spivey-Knowlton, Eberhard, \& Sedivy, 1995; van Berkum, Brown, \& Hagoort, 1999; Yee, Ahmed, \& ThompsonSchill, 2012), such that, for instance, even the blueness of the concept blue is not always activated (Besner, Stolz, \& Boutilier, 1997; Goldfarb, Aisenberg, \& Henik, 2011; Jacoby, Lindsay, \& Hessels, 2003; see Kemmerer, 2014b for discussion) and different modality-specific systems can be recruited for the same object words depending on whether the task stresses visual or action properties (Hoenig et al., 2008). These findings suggest that conceptual processing is not adequately described as the retrieval of fixed conceptual representations but rather as a constructive process in which concepts are "built on the spot" recruiting different kinds of representational systems depending on task demands. In such an account it is conceivable that conceptual processing makes use of basic visual processes to serve high-level (object) word comprehension, at least when detailed visual information is useful. Such an account receives support from recent studies reporting the activation of low-level representations in the motor domain (Hauk, Johnsrude, \& Pulvermüller, 2004; Shtyrov, Butorina, Nikolaeva, \& Stroganova, 2014) and the visual domain (Correia et al., 2014; Desai, Binder, Conant, \& Seidenberg, 2009; Hwang, Palmer, Basho, Zadra, \& Müller, 2009; Mitchell et al., 2008; Ostarek \& Huettig, in press). We are aware that it is not straightforward to draw a clear-cut low versus high level distinction in modalityspecific systems. However, we find it useful to distinguish between processes related to individual local features that tend to be processed in early visual areas and processes related to holistic perception of entire objects that tends to rely on ventral temporal areas.

\section{The Present Study}

On the basis of these considerations, it seems plausible that language comprehension can be achieved by different processing channels that vary dynamically with contextual demands. One such channel, on which we focused in this study, is the access to low-level visual processes. There is some neuroimaging evidence that object words can activate occipital cortex (Correia et al., 2014; Hwang, Palmer, Basho, Zadra, \& Müller, 2009; Lewis \& Poeppel, 2014; Mitchell et al., 2008), and we have recently found that object words rapidly activate basic low-level visual processes related to the mere detection of a stimulus using continuous flash suppression (Ostarek \& Huettig, in press). However, the functional role of low-level visual processes for concrete word comprehension across different processing situations is still unknown. One important step was made by an elegant study (Meteyard, Zokaei, Bahrami, \& Vigliocco, 2008) showing interference of dot patterns moving up versus down with the comprehension of verbs that imply motion in the corresponding direction (e.g., with rise vs. fall). In the present study, we used a paradigm allowing us to test for a functional involvement of basic visual processes during semantic processing of a class of words that rely on visual knowledge more generally. We interfered with basic visual processing while participants were performing different tasks on individual nouns to investigate whether and under what circumstances lowlevel visual representations are causally involved in the comprehension of concrete words. We used dynamic Mondrian-type masks changing at ca. $10 \mathrm{~Hz}$ consisting of rectangles of different colors and sizes. Thereby interference was targeted at visual processes related to edge detection, the perception of colors and orientations, processes that are typically considered low-level as they are the basic building blocks upon which higher-level representations depend.

Although it is generally agreed that knowledge about visual features is crucial for our understanding of concepts referring to physical objects (e.g., Huettig, Mishra, \& Olivers, 2012), the long-standing and crucial question of the nature of the representations underlying this knowledge remains controversial. The flexible conceptual processing account described in the Introduction predicts that different kinds of features are recruited in situations that require different kinds of information. In line with this, we tested the hypothesis that low-level visual processes are recruited specifically in situations where in-depth visual information needs to be retrieved. The rationale we followed in this research is that if (and only if) visual information associated with words is retrieved (at least partly) from low-level visual representations and these are functionally involved in the comprehension process, then interfering with basic visual processing should result in a cost for object word processing. We manipulated the task requirements across three experiments to assess the extent to which dynamic low-level visual interference hindered the comprehension of concrete words when retrieval of visual information was task relevant (concreteness judgment task, Experiment 1), when visual information was irrelevant and semantic processing was minimal (LDT, Experiment 2), and when visual information was irrelevant but semantic processing was necessary (word class judgment task, Experiment 3).

\section{Experiment 1}

In Experiment 1, we measured reaction times (RTs) to highly visually imageable concrete words and low imageability abstract words in a concreteness judgment task with and without concurrent visual interference. We predicted that concrete words should be affected more strongly by visual noise because the affirmative decision that a word refers to a physical object should heavily rely 
on visual information represented in brain regions processing low-level visual information. Although it is conceivable that abstract word meanings are grounded in sensory experience (Kousta, Vigliocco, Vinson, Andrews, \& Del Campo, 2011; Vigliocco et al., 2014), it seems unlikely that visual features are accessed with a degree of specificity comparable to that required for object word processing. RTs to abstract words thus served as a baseline condition allowing us to separate possible general distraction effects of the visual noise manipulation from 'functional interference' effects related specifically to semantic processing of visually dominant concepts. We thus predicted an interaction between word type and visual interference, such that responses to concrete words should be slowed down more than responses to abstract words.

\section{Method}

Participants. Participants in this experiment were 50 native Dutch speakers. They all had normal or corrected-to-normal vision and hearing, were paid and gave written consent. Participant numbers were determined in advance on the basis that approximately 50 participants should yield ample statistical power to detect the effects of interest in this kind of semantic task, given previous work (e.g., Neely, Keefe, \& Ross, 1989). Data collection was stopped when this number was reached. The study was approved by the Ethics Board of the Faculty of Social Sciences of the Radboud University.

Stimuli and apparatus. The visual stimuli were presented on a computer screen (resolution: $1900 \times 720$, refresh rate: $60 \mathrm{~Hz}$ ) in $55 \mathrm{~cm}$ viewing distance using Presentation Software (Version 16.2; see www.neurobs.com). They included a central fixation cross to initiate each trial and the visual interference patterns (random Mondrian-type colorful rectangular shapes changing at 12 $\mathrm{Hz}$ ) which are typically used for continuous flash suppression studies because they interfere strongly with low-level visual processing (see Tsuchiya \& Koch, 2005, for discussion). Fifty-two highly visually imageable concrete words (henceforth "concrete words") and 52 low imageability abstract words (henceforth $a b$ stract words) that were selected on the basis of their high versus low visual imageability were recorded by a female Dutch speaker using Audacity Software. A norming study with the 50 participants of Experiment 1 (conducted after the main experiment) showed that the two word types indeed differed strongly in visual imageability (Likert scale 1-7; concrete words: $M=6.4, S D=0.2$; abstract words: $M=2.9, S D=0.8 ; p<.001)$, which was used as a proxy to gauge how visually dominant the concepts are. ${ }^{1}$ The word types also differed significantly $(p<.001)$ in terms of concreteness ratings (Brysbaert, Stevens, De Deyne, Voorspoels, \& Storms, 2014); on a Likert scale from 1-5 abstract words had a mean of $2.2(0.7)$, concrete words $4.7(0.3)$. Words from the two word types were matched for length (concrete: $M=518 \mathrm{~ms}, S D=$ 72 ms vs. abstract: $M=530 \mathrm{~ms}, S D=79 \mathrm{~ms}, t<1$ ), number of syllables (abstract: $M=1.8, S D=0.5$; concrete: $M=1.6, S D=$ $0.5, t<1$ ), number of phonemes (abstract: $M=5.0, S D=0.9$; concrete: $M=4.8, S D=1.1, t<1$ ), and frequency (abstract: $M=$ 63.6, $S D=70.6$; concrete: $M=64.9, S D=94.9, \mathrm{t}<1$ ) using the SUBTLEX-NL database (Keuleers, Brysbaert, \& New, 2010).

Procedure. At the beginning of each trial a fixation cross appeared at the center of the screen for $800 \mathrm{~ms}$. Immediately afterward participants heard a spoken word accompanied either by a blank screen or by visual noise. Participants were instructed to decide as quickly and as accurately as possible whether the spoken word was concrete or abstract by pressing one of two buttons with their left or right index finger. When a response was made or $2 \mathrm{~s}$ had elapsed after word onset a blank screen replaced the visual noise patterns (when present) and was shown for 1,000 ms after which the next trial started. Every word was presented twice; once with and once without visual noise to obtain a 2 (Word Type; concrete object vs. abstract) $\times 2$ (Visual Condition; flashes vs blank screen) within-subjects design and a total of 208 experimental trials. The experiment was organized in two blocks with all 104 spoken words presented in random order. Each word was accompanied by visual noise either in the first or the second block.

Analysis. Six items were removed because they produced mean error rates greater than $25 \%$ and one because of a technical problem $\left(6.7 \%\right.$ of all trials). ${ }^{2}$ Trials with incorrect responses $(3.8 \%)$ and RTs slower than $2,000 \mathrm{~ms}(0.9 \%)$ were excluded from the analysis. The remaining data set was trimmed for outliers by removing trials with RTs that were more than 2.5 standard deviations from the mean (2.8\%). This amounts to 1,508 trials (14.5\%) removed in total. RTs were analyzed with linear mixed effects models (Baayen, Davidson, \& Bates, 2008) implemented in RStudio (Version 0.98.945, 2009-2013; RStudio, Inc.) using the lme4 package (Bates, Maechler, Bolker, \& Walker, 2014). The full model contained word type and visual condition as well as the interaction between the two as fixed effects and by-participants random slopes and intercepts for both fixed effects and by-items slopes and intercepts for the effect of visual condition. ${ }^{3} \beta$-values (representing estimates based on scaled RTs), $t$ values and $p$ values were obtained by using the function get_pvalues from the psy811 package. Additionally, for the critical interaction the full model was compared with a second model from which only the interaction term was removed using a likelihood ratio test (with the command anova). Finally, to estimate the effect size of the predicted difference in the impact of visual noise on concrete versus abstract words we calculated Cohen's $d$ based on least-square means using the lsmeans package.

\section{Results and Discussion}

There was a main effect of word type $(\beta=-.33, S E=.07$, $t=-4.65, p<.001)$, reflecting faster responses to concrete words. This commonly observed "concreteness effect" is typically attributed to richer representations of concrete words arising from differences in imageability or context availability between concrete and abstract words (Paivio, 1986, 2013, 2014; Schwanenflugel, 1991; Schwanenflugel \& Shoben, 1983; Schwanenflugel, Harnishfeger, \& Stowe, 1988). There was also a main effect of visual condition $(\beta=-.13, S E=.03, t=4.76, p<.001)$ reflecting slower responses on trials with visual noise. Critically, there was a robust interaction between word type and visual condition $\left(\beta=-.1, S E=.04, t=3.00\right.$; likelihood ratio test: $\chi^{2}(1)=9.01$,

\footnotetext{
${ }^{1}$ In particular, participants were asked how strong a mental image they experienced when hearing the word $(1=$ no specific image whatsoever, $7=a$ very strong and clear mental image).

${ }^{2}$ The audio file corresponding to the word verlies (loss) was corrupted such that it was very difficult to recognize it.

${ }^{3}$ A model that additionally included random effects for the interaction of the fixed effects did not converge.
} 
$p=.002$ ). As predicted, visual noise affected responses to concrete words more strongly (see Figure 1). The mean difference was 21 ms with Cohen's $d=0.61$ which is commonly interpreted as a medium effect size.

Our results therefore suggest that concrete words rely more strongly on visual features and, more importantly, that the visual system was recruited for the comprehension of concrete words. The present finding that visual interference disrupts semantic processing of concrete words constitutes direct evidence that basic low-level visual processes can be causally involved in word comprehension. One study along these lines reported that dot patterns moving up or down at near-threshold interfered with the comprehension of verbs with up/down association (rise vs. fall) when their direction was incongruent with the verb meaning (Meteyard, Zokaei, Bahrami, \& Vigliocco, 2008). Whereas that study focused on one particular perceptual feature of a class of verbs, our data speak to the comprehension of concrete words more generally. What is striking about our findings is that the visual interference technique we used specifically interferes with basic low-level processes, as it only consists of horizontal and vertical components and colors, all of which recruit early visual cortical regions (see Yuval-Greenberg \& Heeger, 2013). This indicates that participants did not solely rely on high-level representations but built low-level visual representations on the spot. The recruitment of visual processes typically involved in local feature processing is consistent with the online construction of an idiosyncratic visual representation typical of bottom-up processing and episodic memory retrieval (Danker \& Anderson, 2010; Ueno et al., 2007). We propose that, in the current task situation, spoken words activate processes akin to conscious visual perception in order to solve the sensory judgment task.

\section{Experiment 2}

Though the results of Experiment 1 are striking, it is of crucial importance for our research question to determine to what extent

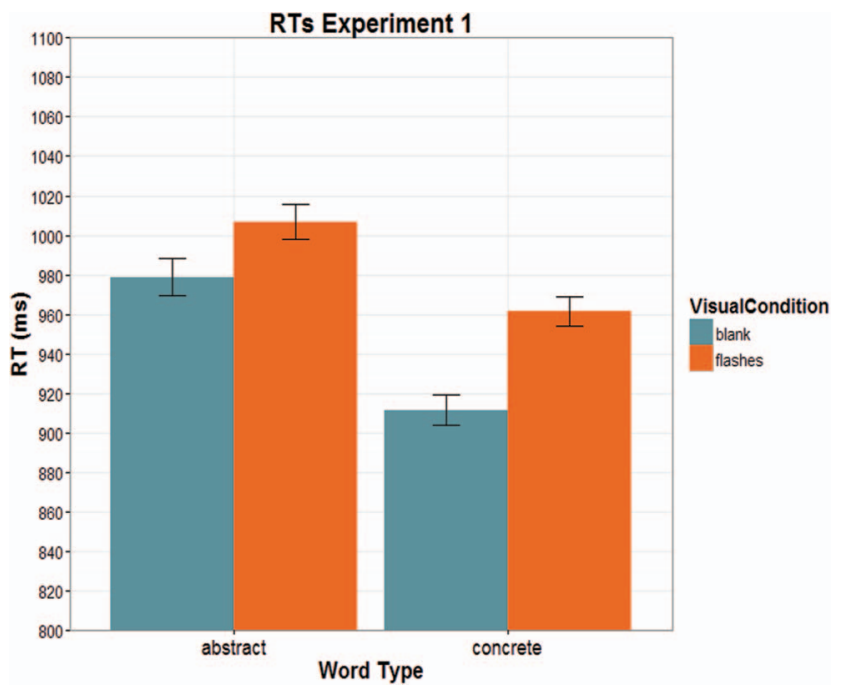

Figure 1. Mean reaction times (RTs) of all four conditions, error bars indicate $95 \%$ confidence intervals. See the online article for the color version of this figure. the visual interference effect reported here is task-dependent. Does spoken object word processing always rely on low-level visual processes? Or, alternatively, are low-level visual representations only involved in spoken word processing when the task requires retrieval of visual information? We tested this issue by repeating the Visual Noise study in an auditory LDT.

Note that although access of semantic information may not be strictly necessary to perform this task, a vast number of lexical decision studies have shown that semantic information is typically accessed and speeds up RTs (e.g., Bentin, McCarthy, \& Wood, 1985; Fischler, 1977; Holcomb \& Neville, 1990; Hutchison, 2003; Perea \& Rosa, 2002; Thompson-Schill, Kurtz, \& Gabrieli, 1998). This makes it an interesting testing ground for the hypothesis that task demands determine what kinds of information are retrieved during language processing: As detailed visual knowledge about word referents is not required to perform a LDT, such accounts predict no specific interference of visual noise with object word processing. If, however, sensory representations are activated automatically and have a functional contribution whenever spoken concrete words are heard (e.g., Gallese \& Lakoff, 2005), the Visual Condition $\times$ Word Type interaction from Experiment 1 should persist.

\section{Method}

Participants. Native Dutch participants $(N=46)$ with normal or corrected-to-normal vision and hearing completed the experiment. They gave written consent and were paid for participation. Sample size and stopping rule were determined in the same way as in Experiment 1.

Stimuli, apparatus, and procedure. Stimuli, apparatus and procedure were identical to Experiment 1, with the following exceptions: 42 instead of 52 items per word type were used and 168 pseudowords added, which resulted in a total of 336 trials. ${ }^{4}$ We used the program Wuggy (Keuleers \& Brysbaert, 2010) to create pseudowords that differed in one or two phonemes from existing words making the lexical decision relatively difficult. Participants had to indicate as quickly and as accurately as possible whether the word they heard was an existing Dutch word or not by pressing one of two buttons.

\section{Results and Discussion}

Four participants had to be excluded because of error rates greater than $25 \%$. The data of the remaining 42 participants were trimmed for errors $(2.4 \%)$, timed-out responses $(1.1 \%)$, and outliers $(2.4 \%)$. The remaining data (a total of $1,103 / 14.3 \%$ of trials was removed) were analyzed in the same way as in Experiment 1 with the exception that the model only included by-participants random slopes for visual condition, as the full model did not converge. There was a main effect of visual condition $(\beta=.24$, $S E=.03, t=8.774, p<.001)$ reflecting slower responses in trials with visual noise but no main effect of word type $(t<1)$ and no statistically significant interaction $(t<1$, see Figure 2$)$.

\footnotetext{
${ }^{4}$ We removed the error-prone items from Experiment 1 and some additional items to keep the duration of the experiment similar to Experiment 1 without sacrificing statistical power, at the same time making sure that the experimental conditions remained well-matched in terms of frequency and so forth.
} 


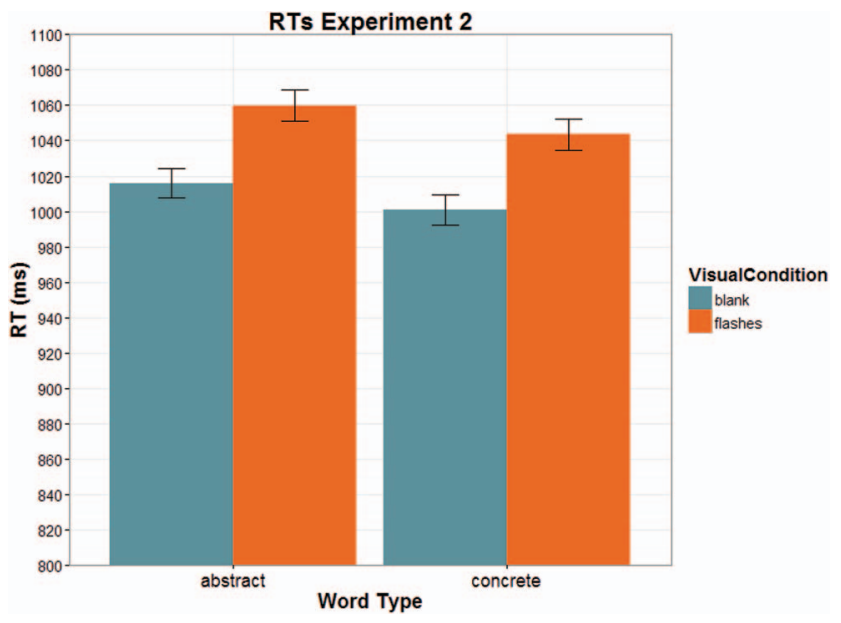

Figure 2. Mean reaction times (RTs) of all four conditions, error bars indicate $95 \%$ confidence intervals. See the online article for the color version of this figure.

These results suggest that in the context of a LDT, visual representations were not functionally involved in object word processing. Experiment 2 thus constrains theories of conceptual processing because it shows that the functional relevance of the visual system for language processing is contingent on task requirements. Our results of course do not conclusively rule out that low-level visual representations were activated in the present task. What we can conclude however is that if they were activated they did not have a detectable functional role. Note that the reason for this is unlikely to be lacking sensitivity of our technique, as Experiment 1 clearly shows that our paradigm can reveal an involvement of low-level visual processes when it is present.

Despite the clear evidence of semantic and (lexical) visual priming in many previous lexical decision studies one may question what information our participants activated in Experiment 2. There is some evidence that words automatically activate nonassociative semantic information, such as information about perceptual features. Some studies found priming effects among words with perceptually similar referents (pizza-coin) using lexical decision (d'Arcais, Schreuder, \& Glazenborg, 1985; Schreuder, d'Arcais, \& Glazenborg, 1984). On the other hand, Pecher, Zeelenberg, and Raaijmakers (1998) pointed out several methodological shortcomings with these data and, using an improved design, only observed this effect when participants performed a perceptual categorization task before the priming experiment but not in a standard LDT. These findings and our present data thus suggest that visual representations are not automatically retrieved whenever spoken words are heard.

\section{Experiment 3}

Because we cannot be sure that the LDT used in Experiment 2 involved semantic access we conducted a third experiment to further investigate the extent to which low-level visual representations are accessed in tasks requiring semantic access. To this end we used a word class decision task (is the word you are presented with a noun or adjective?). Although there are certainly several ways by which the word class of a word can in principle be determined (Kemmerer, 2014a), it seems unlikely that semantic access is completely bypassed. At the same time, it is sufficient to access highly schematic conceptual representations that are largely shared among nouns to solve the task: Nouns are nongradable, nonrelational, temporally stable entities, whereas adjectives refer to gradable qualities and are used for modification (Croft, 2001; Kemmerer, 2014a). As such, there is no need to access detailed visual feature information. If low-level visual representations are automatically accessed and are functionally relevant during semantic spoken word processing regardless of contextual demands, visual noise should nevertheless interfere more with word class decisions to concrete nouns than abstract nouns (i.e., a significant visual noise by word type interaction). Alternatively, according to the flexible processing account, basic visual processes could be recruited specifically in situations where in-depth visual information needs to be retrieved, in which case concrete words should not be affected by visual noise than abstract words.

\section{Method}

Participants. Native Dutch participants $(N=48)$ with normal or corrected-to-normal vision and hearing completed the experiment. They gave written consent and were paid for participation. Sample size and stopping rule were determined in the same way as in Experiment 1 and 2.

Stimuli, apparatus, and procedure. Stimuli, apparatus and procedure were identical to Experiment 1 and 2, with the following exceptions: We used 40 concrete and abstract nouns and 80 adjectives which were all presented twice, resulting in a total of 320 trials. Participants had to indicate as quickly and as accurately as possible whether the word they heard was a noun or an adjective by pressing one of two buttons. Similar to the nouns, adjectives were half concrete (mean concreteness rating: $3.6, S D=0.5$ ) and half abstract $(M=2.6, S D=0.8)$ and differed significantly on this dimension $(p<.001)$, such that these factors were not confounded. Abstract and concrete adjectives were also matched for frequency (concrete: $M=24.6, S D=46.8$; abstract: $M=30.0 ; S D=53.6$; $t<1$ ), number of phonemes (concrete: $M=5.5, S D=2.0$; abstract: $M=5.5, S D=2.0 ; t<1)$, and number of syllables (concrete: $M=1.8, S D=0.8$; abstract: $M=2.0, S D=0.9 ; t<1$ ).

\section{Results}

Two participants had to be excluded due to high error rates $(>25 \%)$. The data from the remaining 46 participants were trimmed for errors $(6.5 \%)$, time-outs $(1.9 \%)$, and outliers $(2.1 \%)$. A total of 1,129 trials $(14.8 \%)$ were thus removed. A linear mixed-effects model (equal in structure to the one used in Experiment 1) revealed a main effect of visual condition $(\beta=.206, t=$ $6.178, S E=.033, p<.001)$ with slower responses in visual noise trials. There was also a main effect of word type $(\beta=-.511$, $S E=.083, t=-6.151, p<.001)$ with slower responses to abstract words, as in Experiment 1. Critically, the interaction between the two was not significant $(t=-1.06)$. Thus, visual noise again affected concrete and abstract words to the same amount (see Figure 3).

Follow-up analysis and discussion. Our results across three experiments indicate that low-level visual representations are only functionally relevant in task situations that require visual informa- 
tion to be retrieved and that other semantic tasks do not rely on their contribution. As Table 1 indicates, visual noise interfered much stronger with concrete object word processing relative to abstract word processing in Experiment 1 but not in Experiments 2 and 3.

To assess statistically whether the effect was specific to the concreteness task, we conducted a post hoc mixed effects model with experiment (Experiment 1 vs. 2 vs. 3) as an additional factor. There was indeed a three-way interaction between visual condition, word type, and experiment (likelihood ratio test: $\left.\chi^{2}[2]=8.412, p=.0149\right)$. The effect of visual noise on concrete words was larger in Experiment 1 compared with Experiment $2(\beta=0.117, S E=.055, t=-2.145, p=.0319)$ and compared with Experiment $3(\beta=-0.147, S E=.055$, $t=-2.681, p=.007)$. The difference between Experiments 1 and 3 is particularly important. Although it is possible that participants relied on phonological processing for the LDT, the noun versus adjective decision task requires semantic access. This would also explain the stronger similarity of Experiment 1 and 3 in terms of RT distributions, as evidenced by a main effect of word type (the "concreteness effect") that was absent in Experiment 2. The absence of an interference effect of visual noise on concrete word processing in a task that requires semantic_but not specifically visual-information supports the view that low-level visual processes are not reflexively recruited for object word comprehension. Rather, they constitute an optional processing channel for situations that rely on the retrieval of visual features. It is important to note that Experiment 1 clearly shows that the interference technique we used is capable of revealing an involvement of low-level visual processes when it is present. Therefore, the absence of interference effects in Experiments 2 and 3 are unlikely due to a lack of sensitivity of the method but rather attributable to the lack of a functional role of low-level visual processes in these tasks.

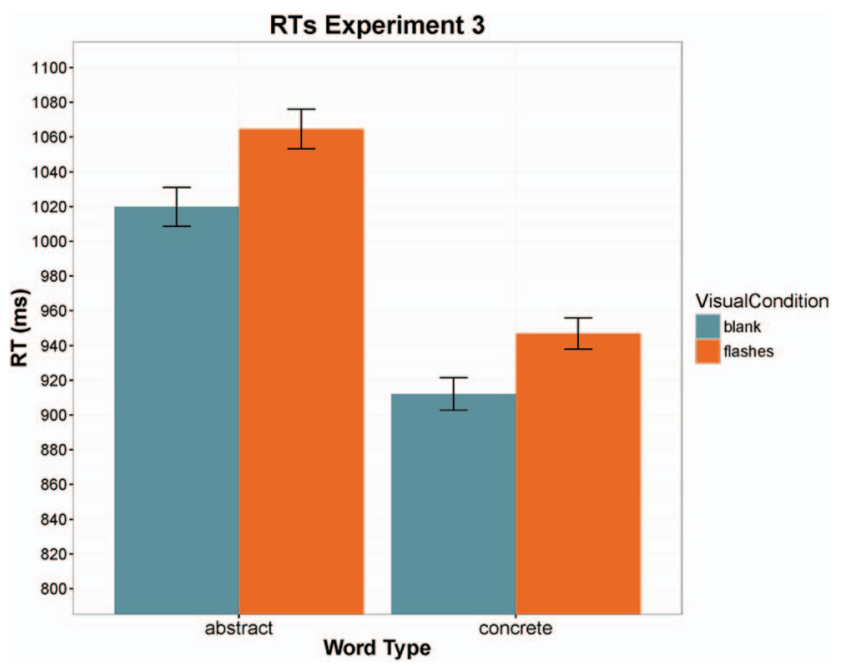

Figure 3. Mean reaction times (RTs) of all four conditions, error bars indicate $95 \%$ confidence intervals. See the online article for the color version of this figure.
Table 1

Overview of Interference Effects Across Experiments

\begin{tabular}{lccc}
\hline \multicolumn{1}{c}{ Word type } & Experiment 1 & Experiment 2 & Experiment 3 \\
\hline Concrete & $50 \mathrm{~ms}$ & $43 \mathrm{~ms}$ & $34 \mathrm{~ms}$ \\
Abstract & $28 \mathrm{~ms}$ & $44 \mathrm{~ms}$ & $45 \mathrm{~ms}$ \\
Interference score & $22 \mathrm{~ms}$ & $-1 \mathrm{~ms}$ & $-11 \mathrm{~ms}$ \\
\hline
\end{tabular}

Note. Interference was calculated for each word type and experiment by subtracting mean reaction times in blank screen trials from mean reaction times in visual noise trials. The interference score represents the difference in interference between both word types.

\section{General Discussion}

In the present study, we used a visual interference paradigm to study the extent to which low-level visual representations are causally involved in spoken word comprehension. Our main finding is that dynamic Mondrian masks that are known to hinder basic low-level visual processing slowed down responses to high-imageability concrete words, as compared to low-imageability abstract words, but only in a task situation that required visual information to be accessed. This result is in line with embodied theories of conceptual processing only to the extent that they are embedded in a flexible processing framework (Hoenig et al., 2008; Lebois et al., 2015). Note that a central aspect of our study is the significant interaction between visual noise and word type (with a bigger effect of visual noise on visually imageable concrete than abstract words). This allows us to separate (potential) general distraction effects of the visual noise manipulation from 'functional interference' effects. Distraction effects likely account for the main effect of visual noise but cannot account for the visual noise by word type interaction observed in Experiment 1.

It is important to point out that we are agnostic with regard to whether the visual representations retrieved in the present study constitute mental imagery (cf. Kosslyn, Ganis, \& Thompson, 2001; Pearson, Naselaris, Holmes, \& Kosslyn, 2015) or what sometimes is referred to as simulations (e.g., Barsalou, 1999, 2008). In our view there is currently no evidence available that conclusively shows that imagery and simulations are distinct. What our findings show is that low-level visual processes are causally involved in semantic processing but (crucially) only when the task requires it, regardless of whether one prefers to call these processes imagery or simulation.

We observed that visual interference affected object word processing more than abstract word processing in a concreteness task (Experiment 1), whereas it affected abstract and concrete words to the same extent in a lexical-decision task (Experiment 2) and a word class decision task (Experiment 3). This suggests that task demands have a strong impact on the processing channels that are used for semantic processing. We are not the first to argue for flexible activation of modalityspecific representations (Hoenig et al., 2008; Lebois et al., 2015; van Dam et al., 2011). What has not been shown before however is that the functional role of low-level visual representations is task-dependent. Our data suggest that visual processes are functionally relevant when in-depth visual information is required (e.g., about the physical properties of a word's referent, as in a concreteness task), while other sources of 
information are preferentially accessed for tasks that do not require such information. This view is supported by a recent study by Edmiston and Lupyan (2017) who found that visual interference impairs participants' ability to make use of visual but not encyclopedic knowledge during word processing.

Our paradigm specifically assessed whether visual representations were necessary for the tasks at hand, not whether they were activated. For instance, in a continuous flash suppression study we recently found evidence that passive listening of object words activates visual processes involved in a task as basic as visual detection (Ostarek \& Huettig, in press). Similarly, a recent magnetoencephalography study (Lewis \& Poeppel, 2014) using an auditory LDT found a correlation between imageability and activity in visual association cortex within the first $200 \mathrm{~ms}$ after word onset. In the light of findings like these, we do not intend to rule out an involvement of the visual system in the LDT and word class decision experiments, but we can tell from the data that it did not have a functional role in these tasks.

Related to this, we do not argue that visual representations are secondary for object word comprehension. To illustrate, nobody would claim that blueness is a secondary feature of "blue," just because a Stroop task only leads to interference in certain conditions, but not others (Besner, Stolz, \& Boutilier, 1997; Goldfarb, Aisenberg, \& Henik, 2011; Jacoby, Lindsay, \& Hessels, 2003; see Kemmerer, 2014b for discussion). What our study shows is that modality-specific visual representations are causally involved in word comprehension if the task situation is conducive for the use of visual information.

To further bolster this conclusion, future studies could investigate whether the amount of interference is predicted by the relevance of visual attributes, which can be assessed with attribute ratings (Binder et al., 2016). This seems to follow from recent fMRI studies establishing a relationship between visual aspects of word meaning and brain activity in visual brain areas (Fernandino, Binder, et al., 2015; Fernandino, Humphries, et al., 2015). Furthermore, different kinds of interference could be used to target specific features, such as color, motion, or shape.

Our data fit within a framework of flexible and dynamical conceptual processing encompassing low-level modalityspecific as well as high-level systems. It would be important for future work to characterize the exact roles, representational nature and interplay of these systems during online language processing. First steps have recently been made in a series of MEG studies that identified enhanced connectivity between anterior temporal lobe (ATL) and modality-specific sensory areas during semantic processing (van Ackeren, 2014). In the light of these findings, two exciting possibilities emerge: (1) Information related to the different multimodal aspects of the given word meaning is retrieved from multiple sensory areas and then converges in ATL where it might be bound (e.g., Patterson, Nestor, \& Rogers, 2007; Pobric, Jefferies, \& Ralph, 2010). In that case ATL would contain compressed multimodal information that may suffice for some semantic tasks. (2) ATL combines contextual factors and stimulus-driven input to pick out those distributed cortical areas that contain relevant information and activates them in concert, possibly binding them via theta-phase locking (Varela, Lachaux, Rodriguez, \& Martinerie, 2001). In that case ATL might not contain semantic knowledge, but have a critical control function necessary for semantic access. Our results suggest that such long-range networks can span all the way into early visual regions, but that their functional role depends heavily on task requirements.

\section{References}

Anderson, A. J., Binder, J. R., Fernandino, L., Humphries, C. J., Conant, L. L., Aguilar, M., . . Raizada, R. D. (2016). Predicting neural activity patterns Associated with sentences using a neurobiologically motivated model ofrsemantic Representation. Cerebral Cortex. Advance online publication. http://dx.doi.org/10.1093/cercor/bhw240

Baayen, R. H., Davidson, D. J., \& Bates, D. M. (2008). Mixed-effects modeling with crossed random effects for subjects and items. Journal of Memory and Language, 59, 390-412. http://dx.doi.org/10.1016/j.jml 2007.12.005

Barsalou, L. W. (1999). Perceptions of perceptual symbols. Behavioral and Brain Sciences, 22, 637-660. http://dx.doi.org/10.1017/S01405 25X99532147

Barsalou, L. W. (2008). Grounded cognition. Annual Review of Psychology, 59, 617-645. http://dx.doi.org/10.1146/annurev.psych.59.103006 .093639

Barsalou, L. W. (2016). On staying grounded and avoiding quixotic dead ends. Psychonomic Bulletin \& Review, 23, 1122-1142. http://dx.doi.org/ 10.3758/s13423-016-1028-3

Bates, D., Maechler, M., Bolker, B. M., \& Walker, S. (2014). lme4: Linear mixed-effects models using Eigen and S4. Retrieved from http://arxiv. org/abs/1406.5823

Bentin, S., McCarthy, G., \& Wood, C. C. (1985). Event-related potentials, lexical decision and semantic priming. Electroencephalography and Clinical Neurophysiology, 60, 343-355. http://dx.doi.org/10.1016/00134694(85)90008-2

Besner, D., Stolz, J. A., \& Boutilier, C. (1997). The Stroop effect and the myth of automaticity. Psychonomic Bulletin \& Review, 4, 221-225. http://dx.doi.org/10.3758/BF03209396

Binder, J. R. (2016). In defense of abstract conceptual representations. Psychonomic Bulletin \& Review, 23, 1096-1108. http://dx.doi.org/10 .3758/s13423-015-0909-1

Binder, J. R., Conant, L. L., Humphries, C. J., Fernandino, L., Simons, S. B., Aguilar, M., \& Desai, R. H. (2016). Toward a brain-based componential semantic representation. Cognitive Neuropsychology, 33(3-4), 130-174. http://dx.doi.org/10.1080/02643294.2016.1147426

Binder, J. R., \& Desai, R. H. (2011). The neurobiology of semantic memory. Trends in Cognitive Sciences, 15, 527-536. http://dx.doi.org/ 10.1016/j.tics.2011.10.001

Binder, J. R., Desai, R. H., Graves, W. W., \& Conant, L. L. (2009). Where is the semantic system? A critical review and meta-analysis of 120 functional neuroimaging studies. Cerebral Cortex, 19, 2767-2796. http://dx.doi.org/10.1093/cercor/bhp055

Bracci, S., \& Op de Beeck, H. (2016). Dissociations and associations between shape and category representations in the two visual pathways. The Journal of Neuroscience, 36, 432-444. http://dx.doi.org/10.1523/ JNEUROSCI.2314-15.2016

Brysbaert, M., Stevens, M., De Deyne, S., Voorspoels, W., \& Storms, G. (2014). Norms of age of acquisition and concreteness for 30,000 Dutch words. Acta Psychologica, 150, 80-84. http://dx.doi.org/10.1016/j .actpsy.2014.04.010

Capitani, E., Laiacona, M., Pagani, R., Capasso, R., Zampetti, P., \& Miceli, G. (2009). Posterior cerebral artery infarcts and semantic category dissociations: A study of 28 patients. Brain: A Journal of Neurology, 132, 965-981. http://dx.doi.org/10.1093/brain/awp013

Chao, L. L., Haxby, J. V., \& Martin, A. (1999). Attribute-based neural substrates in temporal cortex for perceiving and knowing about objects. Nature Neuroscience, 2, 913-919. http://dx.doi.org/10.1038/13217 
Chao, L. L., Weisberg, J., \& Martin, A. (2002). Experience-dependent modulation of category-related cortical activity. Cerebral Cortex, 12, 545-551. http://dx.doi.org/10.1093/cercor/12.5.545

Correia, J., Formisano, E., Valente, G., Hausfeld, L., Jansma, B., \& Bonte, M. (2014). Brain-based translation: FMRI decoding of spoken words in bilinguals reveals language-independent semantic representations in anterior temporal lobe. The Journal of Neuroscience, 34, 332-338. http:// dx.doi.org/10.1523/JNEUROSCI.1302-13.2014

Croft, W. (2001). Radical construction grammar: Syntactic theory in typological perspective. Oxford University Press on Demand.

Damasio, H., Tranel, D., Grabowski, T., Adolphs, R., \& Damasio, A. (2004). Neural systems behind word and concept retrieval. Cognition, 92(1-2), 179-229. http://dx.doi.org/10.1016/j.cognition.2002.07.001

Danker, J. F., \& Anderson, J. R. (2010). The ghosts of brain states past: Remembering reactivates the brain regions engaged during encoding. Psychological Bulletin, 136, 87-102. http://dx.doi.org/10.1037/a0017937

d'Arcais, G. F., Schreuder, R., \& Glazenborg, G. (1985). Semantic activation during recognition of referential words. Psychological Research, 47, 39-49. http://dx.doi.org/10.1007/BF00309217

Desai, R. H., Binder, J. R., Conant, L. L., \& Seidenberg, M. S. (2009). Activation of sensory-motor areas in sentence comprehension. Cerebral Cortex, 20, 468-478. http://dx.doi.org/10.1093/cercor/bhp115

Devlin, J. T., Rushworth, M. F., \& Matthews, P. M. (2005). Categoryrelated activation for written words in the posterior fusiform is task specific. Neuropsychologia, 43, 69-74. http://dx.doi.org/10.1016/j .neuropsychologia.2004.06.013

Devlin, J. T., Russell, R. P., Davis, M. H., Price, C. J., Moss, H. E., Fadili, M. J., \& Tyler, L. K. (2002). Is there an anatomical basis for categoryspecificity? Semantic memory studies in PET and fMRI. Neuropsychologia, 40, 54-75. http://dx.doi.org/10.1016/S0028-3932(01)00066-5

DiCarlo, J. J., \& Cox, D. D. (2007). Untangling invariant object recognition. Trends in Cognitive Sciences, 11, 333-341. http://dx.doi.org/10 $.1016 /$ j.tics.2007.06.010

Edmiston, P., \& Lupyan, G. (2017). Visual interference disrupts visual knowledge. Journal of Memory and Language, 92, 281-292. http://dx .doi.org/10.1016/j.jml.2016.07.002

Fernandino, L., Binder, J. R., Desai, R. H., Pendl, S. L., Humphries, C. J., Gross, W. L., . . Seidenberg, M. S. (2015). Concept representation reflects multimodal abstraction: A framework for embodied semantics. Cerebral Cortex, 26(5), 2018-2034. http://dx.doi.org/10.1093/cercor/ bhv020

Fernandino, L., Humphries, C. J., Seidenberg, M. S., Gross, W. L., Conant, L. L., \& Binder, J. R. (2015). Predicting brain activation patterns associated with individual lexical concepts based on five sensory-motor attributes. Neuropsychologia, 76, 17-26. http://dx.doi.org/10.1016/j .neuropsychologia.2015.04.009

Fischler, I. (1977). Associative facilitation without expectancy in a lexical decision task. Journal of Experimental Psychology: Human Perception and Performance, 3, 18-26. http://dx.doi.org/10.1037/0096-1523.3.1.18

Gallese $^{\dagger}$, V., \& Lakoff, G. (2005). The brain's concepts: The role of the sensory-motor system in conceptual knowledge. Cognitive neuropsychology, 22(3-4), 455-479. http://dx.doi.org/10.1080/0264329044 2000310

Gerlach, C. (2007). A review of functional imaging studies on category specificity. Journal of Cognitive Neuroscience, 19, 296-314. http://dx .doi.org/10.1162/jocn.2007.19.2.296

Goldfarb, L., Aisenberg, D., \& Henik, A. (2011). Think the thought, walk the walk - social priming reduces the Stroop effect. Cognition, 118, 193-200. http://dx.doi.org/10.1016/j.cognition.2010.11.004

Goldinger, S. D., Papesh, M. H., Barnhart, A. S., Hansen, W. A., \& Hout, M. C. (2016). The poverty of embodied cognition. Psychonomic Bulletin \& Review, 23, 959-978. http://dx.doi.org/10.3758/s13423-015-0860-1

Harnad, S. (1990). The symbol grounding problem. Physica D: Nonlinear Phenomena, 42(1-3), 335-346.
Hauk, O., Johnsrude, I., \& Pulvermüller, F. (2004). Somatotopic representation of action words in human motor and premotor cortex. Neuron, 41, 301-307. http://dx.doi.org/10.1016/S0896-6273(03)00838-9

Haxby, J. V., Gobbini, M. I., Furey, M. L., Ishai, A., Schouten, J. L., \& Pietrini, P. (2001). Distributed and overlapping representations of faces and objects in ventral temporal cortex. Science, 293, 2425-2430. http:// dx.doi.org/10.1126/science.1063736

Hoenig, K., Sim, E. J., Bochev, V., Herrnberger, B., \& Kiefer, M. (2008). Conceptual flexibility in the human brain: Dynamic recruitment of semantic maps from visual, motor, and motion-related areas. Journal of Cognitive Neuroscience, 20, 1799-1814. http://dx.doi.org/10.1162/jocn .2008 .20123

Holcomb, P. J., \& Neville, H. J. (1990). Auditory and visual semantic priming in lexical decision: A comparison using event-related brain potentials. Language and Cognitive Processes, 5, 281-312. http://dx.doi .org/10.1080/01690969008407065

Huettig, F., Mishra, R. K., \& Olivers, C. N. (2012). Mechanisms and representations of language-mediated visual attention. Frontiers in Psychology, 2, 394. http://dx.doi.org/10.3389/fpsyg.2011.00394

Hutchison, K. A. (2003). Is semantic priming due to association strength or feature overlap? A microanalytic review. Psychonomic Bulletin \& Review, 10, 785-813. http://dx.doi.org/10.3758/BF03196544

Hwang, K., Palmer, E. D., Basho, S., Zadra, J. R., \& Müller, R. A. (2009). Category-specific activations during word generation reflect experiential sensorimotor modalities. NeuroImage, 48, 717-725. http://dx.doi.org/10 .1016/j.neuroimage.2009.06.042

Jacoby, L. L., Lindsay, D. S., \& Hessels, S. (2003). Item-specific control of automatic processes: Stroop process dissociations. Psychonomic Bulletin \& Review, 10, 638-644. http://dx.doi.org/10.3758/BF03196526

Kemmerer, D. (2014a). Are the motor features of verb meanings represented in the precentral motor cortices? Yes, but within the context of a flexible, multilevel architecture for conceptual knowledge. Psychonomic Bulletin \& Review, 22, 1068-1075. http://dx.doi.org/10.3758/s13423014-0784-1

Kemmerer, D. (2014b). Word classes in the brain: Implications of linguistic typology for cognitive neuroscience. Cortex, 58, 27-51. http://dx.doi .org/10.1016/j.cortex.2014.05.004

Keuleers, E., \& Brysbaert, M. (2010). Wuggy: A multilingual pseudoword generator. Behavior Research Methods, 42, 627-633. http://dx.doi.org/ 10.3758/BRM.42.3.627

Keuleers, E., Brysbaert, M., \& New, B. (2010). SUBTLEX-NL: A new frequency measure for Dutch words based on film subtitles. Behavior Research Methods, 42, 643-650. http://dx.doi.org/10.3758/BRM.42.3 643

Kiefer, M., \& Martens, U. (2010). Attentional sensitization of unconscious cognition: Task sets modulate subsequent masked semantic priming. Journal of Experimental Psychology: General, 139, 464-489. http://dx doi.org/10.1037/a0019561

Kosslyn, S. M., Ganis, G., \& Thompson, W. L. (2001). Neural foundations of imagery. Nature Reviews Neuroscience, 2, 635-642. http://dx.doi .org/10.1038/35090055

Kousta, S. T., Vigliocco, G., Vinson, D. P., Andrews, M., \& Del Campo, E. (2011). The representation of abstract words: Why emotion matters Journal of Experimental Psychology: General, 140, 14-34. http://dx.doi .org/10.1037/a0021446

Lebois, L. A., Wilson-Mendenhall, C. D., \& Barsalou, L. W. (2015). Are automatic conceptual cores the gold standard of semantic processing? The context-dependence of spatial meaning in grounded congruency effects. Cognitive Science, 39, 1764-1801. http://dx.doi.org/10.1111/ cogs. 12174

Lewis, G., \& Poeppel, D. (2014). The role of visual representations during the lexical access of spoken words. Brain and Language, 134, 1-10. http://dx.doi.org/10.1016/j.bandl.2014.03.008 
Mahon, B. Z. (2015). What is embodied about cognition? Language, Cognition and Neuroscience, 30, 420-429. http://dx.doi.org/10.1080/ 23273798.2014.987791

Martin, A. (2007). The representation of object concepts in the brain. Annual Review of Psychology, 58, 25-45. http://dx.doi.org/10.1146/ annurev.psych.57.102904.190143

Martin, A., \& Chao, L. L. (2001). Semantic memory and the brain: structure and processes. Current opinion in neurobiology, 11, 194-201. http://dx.doi.org/10.1016/s0959-4388(00)00196-3

Meteyard, L., Cuadrado, S. R., Bahrami, B., \& Vigliocco, G. (2012). Coming of age: A review of embodiment and the neuroscience of semantics. Cortex, 48, 788-804. http://dx.doi.org/10.1016/j.cortex.2010 .11 .002

Meteyard, L., Zokaei, N., Bahrami, B., \& Vigliocco, G. (2008). Visual motion interferes with lexical decision on motion words. Current Biology, 18(17), R732-R733. http://dx.doi.org/10.1016/j.cub.2008.07.016

Mitchell, T. M., Shinkareva, S. V., Carlson, A., Chang, K. M., Malave, V. L., Mason, R. A., \& Just, M. A. (2008). Predicting human brain activity associated with the meanings of nouns. Science, 320, 11911195.

Neely, J. H., Keefe, D. E., \& Ross, K. L. (1989). Semantic priming in the lexical decision task: Roles of prospective prime-generated expectancies and retrospective semantic matching. Journal of Experimental Psychology: Learning, Memory, and Cognition, 15, 1003-1019. http://dx.doi .org/10.1037/0278-7393.15.6.1003

Nieuwland, M. S., \& Van Berkum, J. J. (2006). When peanuts fall in love: N400 evidence for the power of discourse. Journal of Cognitive Neuroscience, 18, 1098-1111. http://dx.doi.org/10.1162/jocn.2006.18.7.1098

Noppeney, U., Price, C. J., Penny, W. D., \& Friston, K. J. (2006). Two distinct neural mechanisms for category-selective responses. Cerebral Cortex, 16, 437-445. http://dx.doi.org/10.1093/cercor/bhi123

Ostarek, M., \& Huettig, F. (in press). Spoken words can make the invisible visible: Testing the involvement of low-level visual representations in spoken word processing. Journal of Experimental Psychology: Human Perception and Performance.

Paivio, A. (1986). Mental representations: A dual coding approach. New York, NY: Oxford University Press.

Paivio, A. (2013). Imagery and verbal processes. London, Ontario, Canada: Psychology Press.

Paivio, A. (2014). Mind and its evolution: A dual coding theoretical approach. New York, NY: Psychology Press.

Patterson, K., Nestor, P. J., \& Rogers, T. T. (2007). Where do you know what you know? The representation of semantic knowledge in the human brain. Nature Reviews Neuroscience, 8, 976-987. http://dx.doi .org/10.1038/nrn2277

Pearson, J., Naselaris, T., Holmes, E. A., \& Kosslyn, S. M. (2015). Mental imagery: Functional mechanisms and clinical applications. Trends in Cognitive Sciences, 19, 590-602. http://dx.doi.org/10.1016/j.tics.2015 .08 .003

Pecher, D., Zeelenberg, R., \& Raaijmakers, J. G. (1998). Does pizza prime coin? Perceptual priming in lexical decision and pronunciation. Journal of Memory and Language, 38, 401-418.

Perea, M., \& Rosa, E. (2002). The effects of associative and semantic priming in the lexical decision task. Psychological Research, 66, 180194. http://dx.doi.org/10.1007/s00426-002-0086-5

Pobric, G., Jefferies, E., \& Ralph, M. A. L. (2010). Amodal semantic representations depend on both anterior temporal lobes: Evidence from repetitive transcranial magnetic stimulation. Neuropsychologia, 48, 1336-1342. http://dx.doi.org/10.1016/j.neuropsychologia.2009.12.036

Schreuder, R., d'Arcais, G. B. F., \& Glazenborg, G. (1984). Effects of perceptual and conceptual similarity in semantic priming. Psychological Research, 45, 339-354. http://dx.doi.org/10.1007/BF00309710

Schwanenflugel, P. (1991). Why are abstract concepts hard to understand?
In P. J. Schwanenflugel (Ed.), The psychology of word meaning (pp. 223R732-250). Hillsdale, New Jersey.

Schwanenflugel, P. J., Harnishfeger, K. K., \& Stowe, R. W. (1988). Context availability and lexical decisions for abstract and concrete words. Journal of Memory and Language, 27, 499-520. http://dx.doi .org/10.1016/0749-596X(88)90022-8

Schwanenflugel, P. J., \& Shoben, E. J. (1983). Differential context effects in the comprehension of abstract and concrete verbal materials. Journal of Experimental Psychology: Learning, Memory, and Cognition, 9, 82-102. http://dx.doi.org/10.1037/0278-7393.9.1.82

Shinkareva, S. V., Malave, V. L., Mason, R. A., Mitchell, T. M., \& Just, M. A. (2011). Commonality of neural representations of words and pictures. NeuroImage, 54, 2418-2425. http://dx.doi.org/10.1016/j neuroimage.2010.10.042

Shinkareva, S. V., Mason, R. A., Malave, V. L., Wang, W., Mitchell, T. M., \& Just, M. A. (2008). Using FMRI brain activation to identify cognitive states associated with perception of tools and dwellings. PLoS ONE, 3(1), e1394. http://dx.doi.org/10.1371/journal.pone.0001394

Shtyrov, Y., Butorina, A., Nikolaeva, A., \& Stroganova, T. (2014). Automatic ultrarapid activation and inhibition of cortical motor systems in spoken word comprehension. Proceedings of the National Academy of Sciences of the United States of America, 111(18), E1918-E1923. http:// dx.doi.org/10.1073/pnas.1323158111

Simanova, I., Hagoort, P., Oostenveld, R., \& van Gerven, M. A. (2014). Modality-independent decoding of semantic information from the human brain. Cerebral Cortex, 24, 426-434. http://dx.doi.org/10.1093/ cercor/bhs324

Solomon, K. O., \& Barsalou, L. W. (2004). Perceptual simulation in property verification. Memory \& Cognition, 32, 244-259. http://dx.doi .org/10.3758/BF03196856

Tanenhaus, M. K., Spivey-Knowlton, M. J., Eberhard, K. M., \& Sedivy, J. C. (1995). Integration of visual and linguistic information in spoken language comprehension. Science, 268, 1632-1634. http://dx.doi.org/10 1126/science. 7777863

Thompson-Schill, S. L. (2003). Neuroimaging studies of semantic memory: Inferring "how" from "where." Neuropsychologia, 41, 280-292. http://dx.doi.org/10.1016/S0028-3932(02)00161-6

Thompson-Schill, S. L., Kurtz, K. J., \& Gabrieli, J. D. (1998). Effects of semantic and associative relatedness on automatic priming. Journal of Memory and Language, 38, 440-458. http://dx.doi.org/10.1006/jmla .1997 .2559

Tranel, D., Damasio, H., \& Damasio, A. R. (1997). A neural basis for the retrieval of conceptual knowledge. Neuropsychologia, 35, 1319-1327. http://dx.doi.org/10.1016/S0028-3932(97)00085-7

Tsuchiya, N., \& Koch, C. (2005). Continuous flash suppression reduces negative afterimages. Nature Neuroscience, 8, 1096-1101. http://dx.doi .org/10.1038/nn1500

Ueno, A., Abe, N., Suzuki, M., Hirayama, K., Mori, E., Tashiro, M., . . Fujii, T. (2007). Reactivation of medial temporal lobe and occipital lobe during the retrieval of color information: A positron emission tomography study. NeuroImage, 34, 1292-1298. http://dx.doi.org/10.1016/j neuroimage.2006.10.022

van Ackeren, M. J. (2014). Oscillatory neuronal dynamics during lexicalsemantic retrieval and integration (Unpublished doctoral dissertation) Department of Psychology, University of York, York, UK.

Van Berkum, J. J., Brown, C. M., \& Hagoort, P. (1999). Early referential context effects in sentence processing: Evidence from event-related brain potentials. Journal of Memory and Language, 41, 147-182. http:// dx.doi.org/10.1006/jmla.1999.2641

van Dam, W. O., van Dijk, M., Bekkering, H., \& Rueschemeyer, ShirleyAnn. (2011). Flexibility in embodied lexical-semantic representations. Human brain mapping, 33, 2322-2333. http://dx.doi.org/10.1002/hbm .21365 
Varela, F., Lachaux, J. P., Rodriguez, E., \& Martinerie, J. (2001). The brainweb: Phase synchronization and large-scale integration. Nature Reviews Neuroscience, 2, 229-239. http://dx.doi.org/10.1038/35067550

Vigliocco, G., Kousta, S. T., Della Rosa, P. A., Vinson, D. P., Tettamanti, M., Devlin, J. T., \& Cappa, S. F. (2014). The neural representation of abstract words: The role of emotion. Cerebral Cortex, 24, 1767-1777. http://dx.doi.org/10.1093/cercor/bht025

Yee, E., Ahmed, S. Z., \& Thompson-Schill, S. L. (2012). Colorless green ideas (can) prime furiously. Psychological Science, 23, 364-369. http:// dx.doi.org/10.1177/0956797611430691
Yuval-Greenberg, S., \& Heeger, D. J. (2013). Continuous flash suppression modulates cortical activity in early visual cortex. The Journal of Neuroscience, 33, 9635-9643. http://dx.doi.org/10.1523/JNEUROSCI $.4612-12.2013$

Received June 14, 2016

Revision received November 4, 2016

Accepted November 5, 2016 